\title{
High resolution receiver function imaging of the seismic velocity discontinuities in the crust and the uppermost mantle beneath southwest Japan
}

\author{
Makiko Yamauchi ${ }^{1}$, Kazuro Hirahara ${ }^{1}$, and Takuo Shibutani ${ }^{2}$ \\ ${ }^{1}$ Graduate School of Environment, Nagoya University, Nagoya 464-8602, Japan \\ ${ }^{2}$ Disaster Prevention Research Institute, Kyoto University, Kyoto 611-0011, Japan \\ (Received December 4, 2002; Revised January 8, 2003; Accepted January 20, 2003)
}

\begin{abstract}
Clear images of the seismic velocity discontinuities in the crust and the uppermost mantle beneath southwest Japan have been obtained with Receiver Function (RF) analyses of teleseismic waveforms observed at extraordinary dense short-period and broadband stations. For imaging, we construct several 2-D profiles of depth-transformed RFs to delineate the fine crustal structure and the 3-D configuration of the Philippine Sea plate (PHS). The Moho is clearly seen and locally depressed just beneath the Chugoku Mountains. The Conrad, the velocity discontinuity within the crust, in the northern Kinki region is recognized and depressed just beneath the Chugoku Mountains as well as the Moho. RF analyses also clearly elucidate the largely contorted configuration of the PHS including aseismic portions. The PHS subducts aseismically under the western Chugoku region with a high dip angle of 35 degrees at least to a depth of $65 \mathrm{~km}$. In the western Kii Peninsula, it descends steeply to a depth of $90 \mathrm{~km}$ with some curvature, while it subducts with a low dip of 20 degrees to a depth of $60 \mathrm{~km}$ from the eastern Kii Peninsula to the Lake Biwa.
\end{abstract}

\section{Introduction}

It is of great significance to grasp the detailed structure of the crust and the upper mantle including seismic velocity discontinuities beneath southwest Japan (see Fig. 1) in view of understanding the mechanism of great interplate earthquakes repeatedly occurring along the Nankai trough and large inland ones in active faults, which have brought out great disasters. So far, the complex structure beneath southwest Japan has been investigated for the past a few decades based on seismic activity, travel time tomography and the reflection or refraction surveys using artificial explosion sources. The studies based on seismicity, however, cannot detect any possible aseismic slab. Travel time tomography studies, assuming the gradual change of the structure, have not provided clear image of seismic velocity discontinuity. Reflection or refraction surveys have the restrict limitation of the study areas and the deeper portions of the subducting slab cannot be investigated.

There have recently been deployed three nation-wide seismic networks over the Japan Islands, short-period Hi-net (634 stations), broadband F-net (65 stations) and shortperiod and broadband J-array (269 stations). The former two networks are operated by NIED (National Research Institute for Earth Science and Disaster Prevention) and the latter by the Japanese universities and JMA (Japan Meteorological Agency), and the number of stations in the former two networks is increasing still at present. These networks realize the high density of seismic stations in the whole Japan Islands. Especially in southwest Japan, the highest station den-

Copy right(c) The Society of Geomagnetism and Earth, Planetary and Space Sciences (SGEPSS); The Seismological Society of Japan; The Volcanological Society of Japan; The Geodetic Society of Japan; The Japanese Society for Planetary Sciences. sity is realized and clear teleseismic waveforms have been observed.

This paper, using such high-density and high-quality waveform data, reveals the detailed structure of the seismic velocity discontinuities in the crust and the uppermost mantle beneath southwest Japan with RF analyses. Although RF imaging beneath the Japan islands has been already executed by Li et al. (2000), they aim mainly the imaging of the upper mantle down to a depth of $1000 \mathrm{~km}$ with only broadband data. In this study we use a larger amount of data including short-period data observed at incomparably dense stations, which dramatically raises the spatial resolution of imaging structure beneath the whole southwest Japan. Shiomi (2002) has executed the detailed RF analyses using more events than our study. His detailed analyses have, however, been confined in the Shikoku and the Chugoku regions using the data observed only at Hi-net stations. Our analyses extend to the Kinki region and the Kii Peninsula using the data observed at three network stations.

\section{Data and Method}

In this study, we use a large number of teleseismic waveforms observed at 117 stations of Hi-net, 96 stations of Jarray and 4 stations of F-net in southwest Japan, whose station spacing reaches a few kilometers, and the distribution is shown in Fig. 1. Figure 2 and Table 1 summarize the event distribution and the number of events for networks of Hi-net, $\mathrm{J}$-array and F-net used in our analyses.

RFs effectively pick up the P-S waves converted at seismic velocity discontinuities just beneath a station among the whole observed phases. We employ waveforms with a duration of 95 seconds from 5 seconds before to 90 seconds 
Table 1. Number of the stations and events used in this study for respective networks. There is also included type of seismograms, and the period and magnitude range for events.

\begin{tabular}{c|c|ccc}
\hline & & Hi-net & J-array & F-net \\
\hline \multirow{2}{*}{ Networks } & Number of stations & 117 & 96 & 4 \\
& Type of seismograms & short-period & short-period broadband & broadband \\
\hline \multirow{2}{*}{ Event data } & Period & $00 / 10-02 / 06$ & $96 / 11-00 / 01$ & $96 / 11-00 / 01$ \\
& $M>$ & 5.5 & 6.0 & 6.0 \\
& Number of events & 72 & 91 & 94 \\
\hline
\end{tabular}

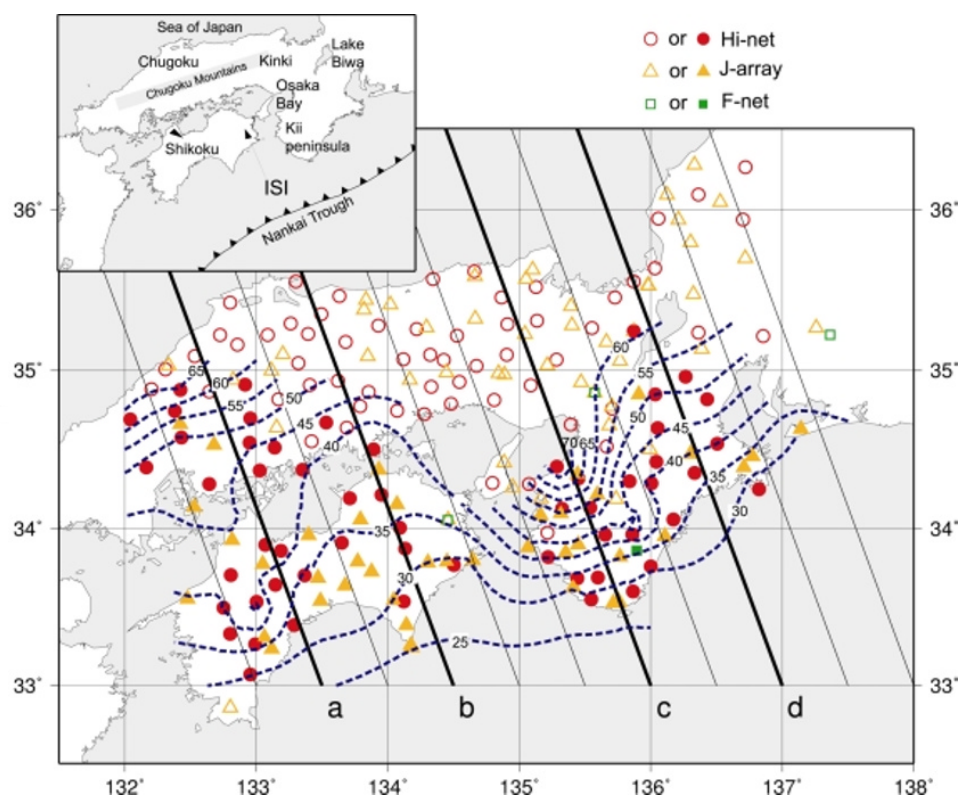

Fig. 1. Location of the stations and the 2-D RF profiles, and the contour map of the upper boundary of the PHS estimated in this study. Each symbol represents the network to which the station belongs. The filled or open symbols indicate the stations where the depth of the upper boundary of the PHS is estimated or not, respectively. The solid lines indicate the locations of 11 lines along which the 2-D RF profiles are constructed, and 4 lines with the labels of a-d show the ones along which the results of 2-D RF profiles are displayed in this paper. In the inserted figure, are given the region names used in this study.

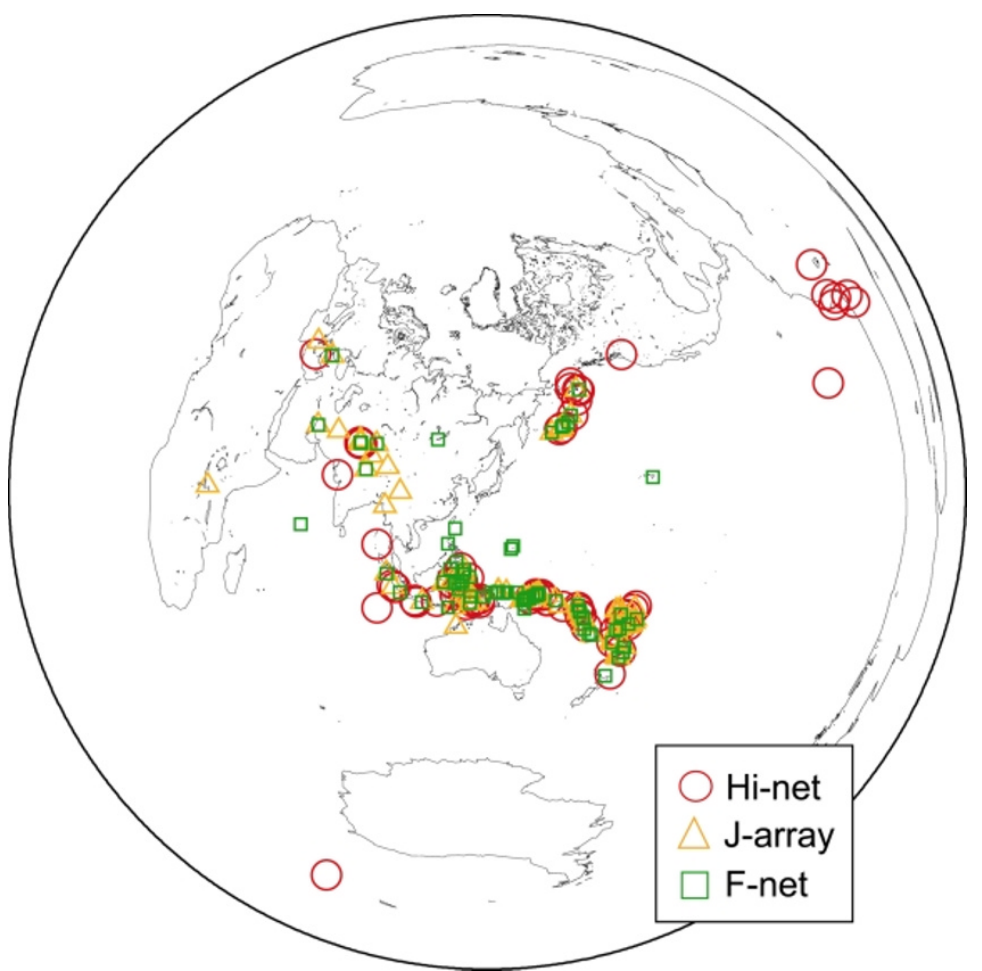

Fig. 2. Equidistant distribution of the events used in this study. Each symbol represents the network whose stations observe the event. 
a

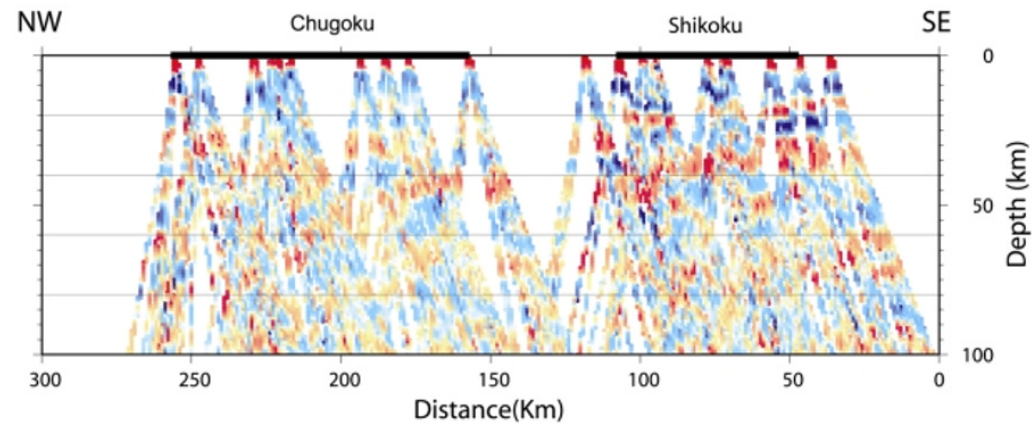

b
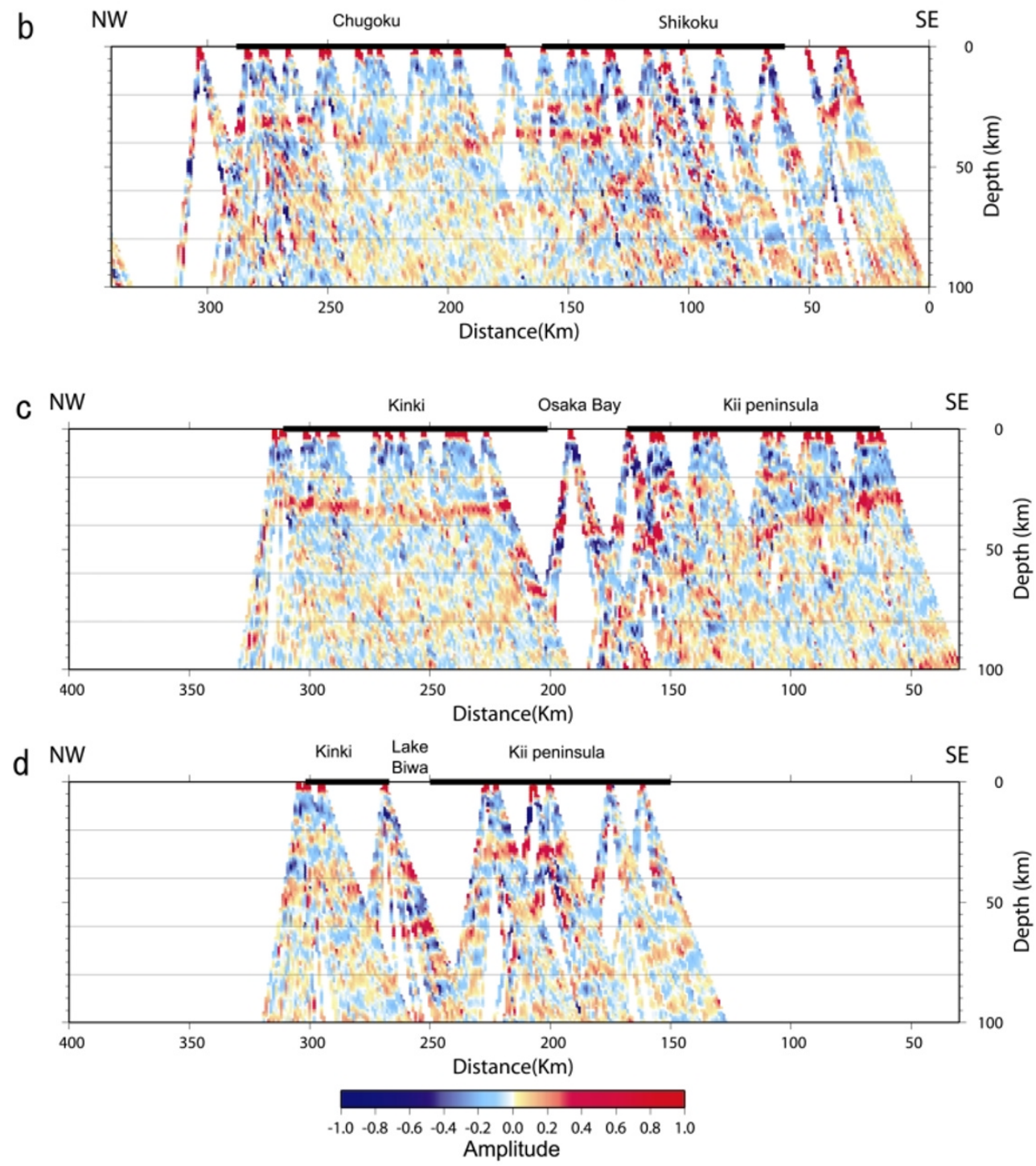

Fig. 3. Obtained 2-D RF profiles. (a)-(d) correspond to RFs along the lines of a-d shown in Fig. 1. The color bar from red to blue indicates the positive to negative normalized by respective first large amplitude.

after the onset of P-waves to construct RFs. The water level method (Langston, 1977, 1979), where the value of the water level is 0.01 , is applied to original waveforms in the frequency domain. We also apply Gaussian filter for high-cut filtering of $1 \mathrm{~Hz}$ and $1.6 \mathrm{~Hz}$ for short period data of Hi-net and J-array and broadband data of J-array and F-net, respectively.

Assuming that each later phase in a RF is the wave converted from $\mathrm{P}$ to $\mathrm{S}$ at a depth, we transform the time domain $\mathrm{RF}$ into the depth domain one along each ray path in a ref- erence velocity model. IASP91 model is used in this study. The differences of the depth of each phase by transformation in possible different velocity models may be a measure of the estimation error of absolute depth of each discontinuity. Therefore, at ISI, a station in Fig. 1, we compare the depth domain RF using IASP91 to that using two test models. One is the resultant velocity model of detailed RF analysis (Shibutani, 2001). This velocity model has some sediments at the surface, the 5 percent faster upper crust, the lower crust with the same velocity as that of IASP91 and a 
6 percent lower velocity zone from 40 to $45 \mathrm{~km}$. The other is JMA model, in which the velocity gradually increases instead of some clear discontinuities. In the resultant depth domain RFs by the first and second test models, a phase converted at the possible Moho in the descending PHS sifts $1 \mathrm{~km}$ more shallowly and $2 \mathrm{~km}$ more deeply, respectively. Hence we recognize the estimation error for the absolute values of the depths of each discontinuity is about $3 \mathrm{~km}$.

In the RFs arranged in this way, we can find some coherent phases. Those phases are further more enhanced by applying Singular Value Decomposition filter (Chevrot and Girardin, 2000). This filter removes the incoherent noises among the waveforms by a truncated sum over first few eigenimages. We reconstruct RFs with the first 6 eigenimages.

We set 11 lines, as displayed in Fig. 1, to construct 2-D RF profiles. The RFs at the stations within a width of $25 \mathrm{~km}$ from each cross section are selected. Then the amplitudes of the depth domain RFs are projected in the $1 \mathrm{~km}$ by $1 \mathrm{~km}$ cells on the plane along each line, and then averaged.

\section{Results and Discussion}

In Figs. 3(a)-3(d), we show the results only along the representative 4 lines that have remarkable features. Each figure displays the depth domain RF profile along each line ' $a$ ' to 'd' in Fig. 1 at depths of $0-100$ km. And Figs. 4(a), 4(b), 4(c) and 4(d) show the figures in which seismic activity (JMA, 1995-2002, M > 1) in each area and some our interpretations are added to Figs. 3(a), 3(b), 3(c) and 3(d), respectively. We mainly pay attention to the results down to a depth of $70 \mathrm{~km}$, because the RF results below the depth are contaminated by multiple P-S phases at discontinuities existing in the upper portion.

\subsection{Profile a}

In Fig. 3(a), three portions of consecutive positive amplitudes indicated by red in RFs can be clearly traced and we can draw three lines in Fig. 4(a). These positive amplitude portions are interpreted as P-S converted phases at velocity discontinuities corresponding to the Conrad (line $\mathrm{C}$ ), the Moho (line $\mathrm{M}$ ) and the Moho in the descending PHS (line P) by referring to seismicity. The inland Moho is not seen beneath the southern Shikoku region. But it appears beneath the northern Shikoku, and steeply goes down just under the southern Chugoku Mountains, and then it is getting shallower towards the Sea of Japan. The velocity discontinuity within the crust, which is usually called the Conrad, is not always found beneath the Japan islands. We recognize, however, the positive RF amplitudes located at depths corresponding to the Conrad along most of lines in southwest Japan, and we simply call the Conrad for the corresponding discontinuity in this study. The Conrad lies at depths between 15 and $20 \mathrm{~km}$ throughout the profile. On the other hand, the PHS with a low dip angle of 10 degrees, which can be also traced by seismic activity, suddenly changes its dip to 35 degrees just under the southern Chugoku Mountains, and subducts deeper as an aseismic slab to at least $65 \mathrm{~km}$ depth. In this region, Nakanishi (1980) points out the existence of aseismic slab and recent tomographic studies (e.g. Yamane et al., 2000) have shown the same structure. Our RF analyses provide far clearer image of the dipping PHS.

In this paper we regard the portions indicated by red with positive RF amplitudes produced by the P-S phases converted at the high to low seismic velocity discontinuity as the upper boundary of the PHS. Existence of the low velocity zone at the top of the PHS, which is the oceanic crust, is suggested by explosion studies (e.g. Kurashimo et al., 2002) and in a detailed RF study (Shibutani, 2001). Accordingly the red portions with positive RF amplitudes in figures indicate the lower boundary of the oceanic crust (i.e., the Moho) within the PHS, but not the top of the PHS. However, we can trace clearly in figures only the positive amplitude (red) portions instead of the negative amplitude (blue) ones. Thus, we adopt the positive RFs as indicators of the location of the PHS although they do not correspond to the plate boundary but the Moho in the PHS.

\subsection{Profile b}

In Fig. 3(b), we also find three consecutive positive RF portions and those can be indicated by lines of $\mathrm{C}, \mathrm{M}$ and $P$ in Fig. 4(b). According to Ito (1999) that states inland earthquakes occurs in the upper crust, comparing with the upper crustal seismicity, we regard the line $\mathrm{C}$ as the Conrad. The Conrad is seen beneath the Chugoku region at depths of $12-20 \mathrm{~km}$. Line M1 seen beneath the northern Shikoku at depths of $20-30 \mathrm{~km}$ and line M2 seen beneath the northern Chugoku at depths of 30-40 km indicate the Moho, which are depressed beneath the central Chugoku region. And then we identify the line P that dips northwards with a very low dip angle from the Nankai trough side as the configuration of the PHS. Even we take account of the estimation error of the absolute depth as stated in Section 2, line P seems to be located above the deeper seismic activity beneath the Shikoku region. Therefore earthquakes in this profile seem to occur within the mantle of the PHS, which is consistent with Baba et al. (2002). Shiomi (2002) has recently executed more detailed RF analyses in the Shikoku and Chugoku regions and obtained the results on the PHS configuration in these regions, which are similar to our study.

\subsection{Profile c}

The most remarkable features in Fig. 3(c) are the clear positive RF traces in the Kinki region and the steeply dipping ones beneath the Kii Peninsula. The clear line $\mathrm{M}$ in Fig. 4(c), which is interpreted to be the Moho, is located at depths of $35 \mathrm{~km}$ beneath the Kinki region and has the deepest in the central Kinki region. It is also located at a depth of $40 \mathrm{~km}$ beneath the northwestern Kii Peninsula, though it is not clearer than in the Kinki region. It is noted that the Moho is depressed beneath the Osaka Bay and there seems to exist a gap of $5 \mathrm{~km}$ in the Moho depth between the inland Kinki region and the Osaka Bay. Line C drawn in Fig. 4(c) is regarded as the Conrad by referring to the upper crustal seismicity, which also goes down beneath the central Kinki region as well as the Moho. According to Ito (1999), the inland large earthquakes are likely to occur in the region where the lower cut off depth of the crustal seismicity and/or the Conrad depth are abruptly changed laterally. The discontinuity corresponds to the Conrad as the cutoff depth is usually shallower than the depth of the Conrad, which can be seen in this figure, but both are related to the top of the ductile lower crust. Therefore, the detailed investigation of the undulation of the Conrad enables us to know the areas where large inland events are likely to occur. RF method has proved to be 
a

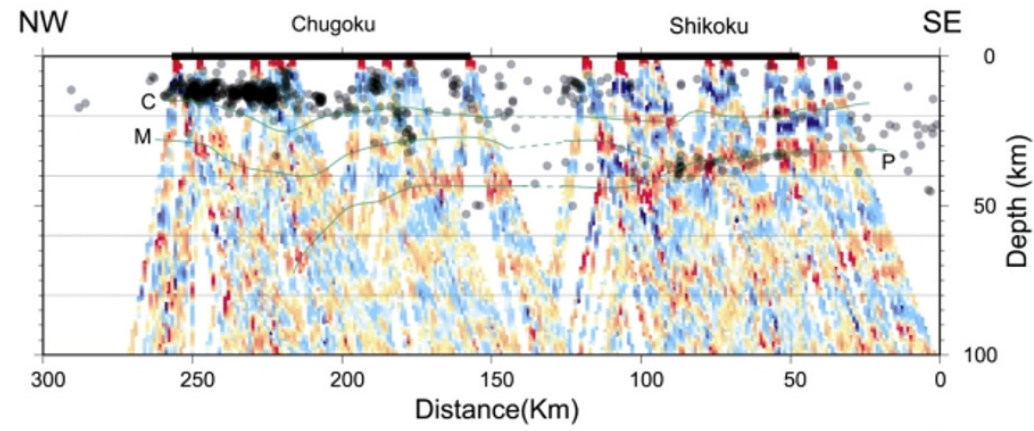

$\mathrm{b}$
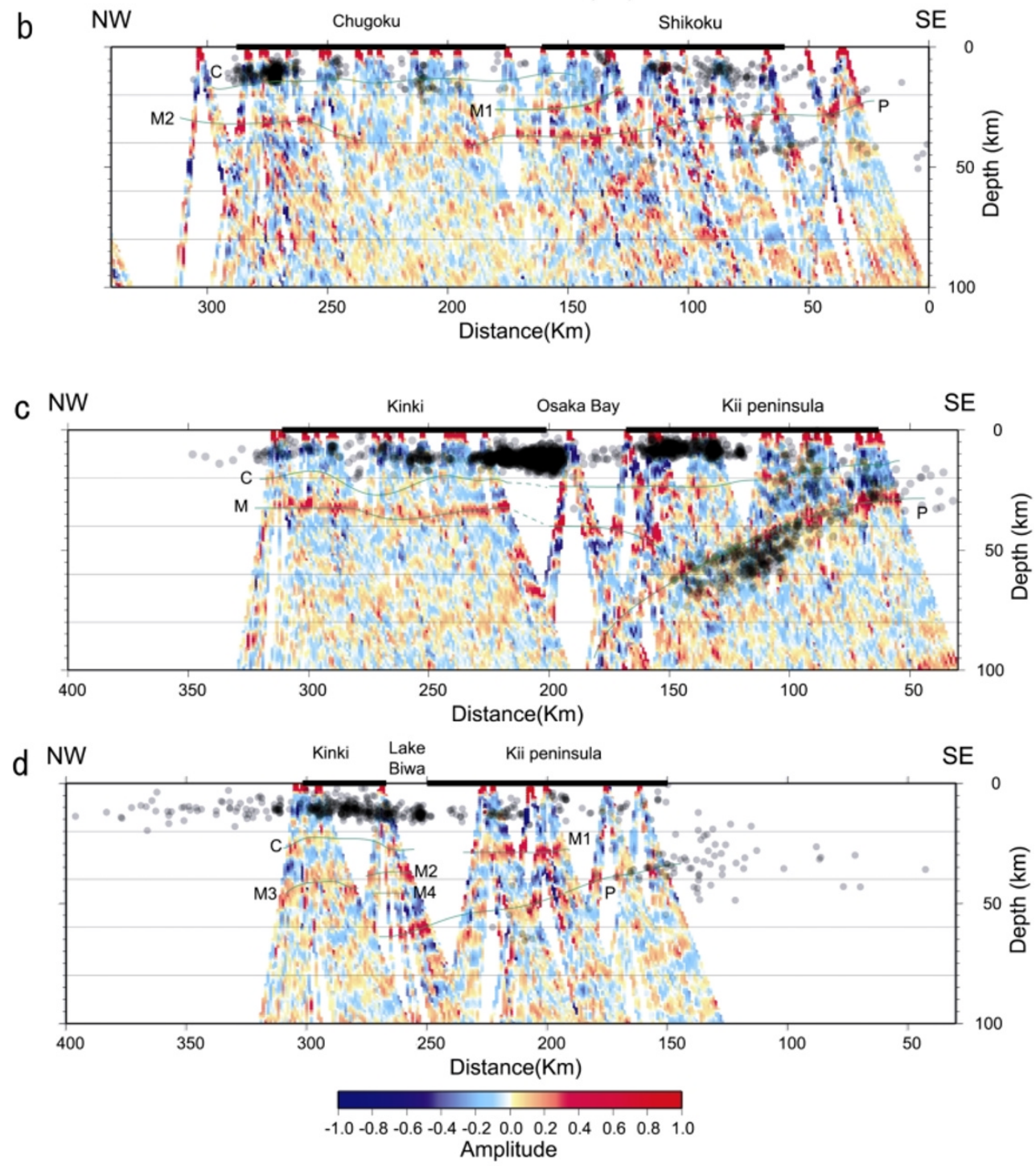

Fig. 4. 2-D RF profiles with seismic activity of JMA. The positive RF traces with lines denoted by $\mathrm{C}, \mathrm{M}$ and $\mathrm{P}$ are interpreted to correspond to the Conrad, the Moho and the upper boundary of the PHS.

a useful way to know the detailed undulation of the Conrad.

Positive RF traces denoted by the line P in Fig. 4(c), which closely correspond to the deeper seismic activity down to a depth of $60 \mathrm{~km}$, shows the dipping PHS with high dip angles. The line is located at about $30 \mathrm{~km}$ beneath the southern tip of the Kii Peninsula, and is steeply dipping to at least a depth of $90 \mathrm{~km}$. Furthermore, this line seems to have some curvature in the deep aseismic portion.

\subsection{Profile d}

It can be found in Fig. 3(d) that profile $d$ has less spatial resolution than the other profiles due to the sparse distribution of stations. We draw line C in Fig. 4(d) and it is seen beneath the Kinki region and lying around 5-10 km under the crustal seismicity. Therefore we define line $\mathrm{C}$ as the Conrad. A group of lines M1 to M3 in Fig. 4(d), which appears at the northern root of the Kii Peninsula and dips to the Sea of Japan with a low dip of 10 degrees, can be regarded as the Moho. In this profile the Moho beneath the Kinki region is 
about $10 \mathrm{~km}$ deeper than that in profile $\mathrm{c}$ of Fig. 4(c), which is consistent with the observed Bougure gravity anomaly (e.g. Hagiwara, 1967). Furthermore, beneath the Lake Biwa line M4 is seen under line M2. The line P drawn in Fig. 4(d), which dips from the Nankai trough side to the Sea of Japan in parallel to the Moho, is seen as the dipping PHS. It is clearly recognized that this line $\mathrm{P}$ extends down to a depth of $60 \mathrm{~km}$ beneath the Lake Biwa. Aseismic Philippine Sea slab, which is diving into the region beneath the Lake Biwa with a relatively low dip angle, is also pointed out by Hori et al. (1985).

\subsection{Contour map of the upper boundary of the PHS}

We produce the contour map of the upper boundary of the PHS by interpolating the visually inspected depths of lines $\mathrm{P}$ in Figs. 4(a)-4(d) along the respective 11 profiles. The resulting contours are drawn by blue dashed curves in Fig. 1. The stations where the PHS depth can be visually obtained are shown by filled symbols. Therefore the contour is relievable in the regions where the stations with filled symbols are densely distributed.

In the Kii Peninsula, our contour shape, which shows gentle and steep dips in the eastern and western Kii Peninsula respectively, is consistent with that in the past study based on seismic activity and analyses of later phases (e.g. Nakamura et al., 1997; Hori et al., 1985). On the other hand, in the Shikoku region our study shows an interesting configuration. In the western Shikoku, the PHS is somehow concaved toward the Nankai trough side comparing to those in the surrounding regions. To the contrary, in the eastern Shikoku and the southern tip of the eastern Chugoku region, the dip angle of the PHS is lower, that is, the PHS swells beneath this region.

We can draw the contour depth of the aseismic portion of the PHS down to a depth of $60 \mathrm{~km}$, which cannot be detected based on seismic activity in the Chugoku region and around the Lake Biwa. This is a great progress in the understanding seismic tectonics in these regions.

As indicated by the contour map in Fig. 1, the PHS including the aseismic portion down to a depth of $60 \mathrm{~km}$ or greater is largely contorted with the concave portions in the western Kii Peninsula and the western Shikoku regions. The features found beneath the Shikoku and the Chugoku regions are also found in more detailed analyses of Shiomi (2002). We newly reveal the PHS configuration beneath the Kii Peninsula and the Kinki regions, in addition to these regions.

\section{Conclusion}

We analyze a large amount of teleseismic waveforms observed at dense stations of Hi-net, J-array and F-net using RF method, to reveal the detailed structure of the crust and the dipping PHS beneath southwest Japan. By constructing 2-D profiles of SVD filtered depth domain RFs, we have obtained far clearer image of the velocity discontinuities corresponding to the Conrad and the Moho and the configuration of the dipping PHS. The notable feature of the Moho configuration is that it goes down just beneath the Chugoku Mountains in the western Chugoku and the northern Kinki regions. More- over the Conrad in the Kinki region is also depressed just beneath the Chugoku Mountains. On the other hand, the aseismic PHS is detected beneath the Chugoku region with a high dip of 35 degrees and beneath the Lake Biwa with a low dip of 20 degrees. In the Kii Peninsula we obtain the extremely clear image of the dipping PHS with some curvature subducting to at least a depth of $90 \mathrm{~km}$ beneath the northern Kii Peninsula or the Osaka Bay.

Acknowledgments. We are so grateful to K. Obara and K. Shiom in NIED who kindly help us to use the Hi-net data and give us helpful comments. We gratefully acknowledge fruitful discussions with T. Matsuzawa on several points in the paper. Our gratitude is also due to the Japanese university group, JMA and NIED for the use of the data of J-array and F-net. We use the unified hypocentral data that was collected by JMA and MEXT. This study is financially supported by Grad-in-Aid for Scientific Research (B) (1434013) of MEXT.

\section{References}

Baba, T., Y. Tanioka, P. R. Cummins, and K. Uhira, The slip distribution of the 1946 Nankai earthquake estimated from tsunami inversion using a new plate model, Phys. Earth Planet Int., 132, 59-73, 2002.

Chevrot, S. and N. Giardin, On the detection and identification on converted and reflected phases from receiver functions, Geophys. J. Int., 141, 801$808,2000$.

Hagiwara, Y., Analyses of gravity values in Japan, Bull. Earthq. Res. Inst., Univ. Tokyo, 45, 1091-1228, 1967.

Hori, S., H. Inoue, Y. Fukao, and M. Ukawa, Seismic detection of the untransformed 'basaltic' oceanic crust subducting into the mantle, Geophys. J. R. astr. Soc., 83, 169-197, 1985.

Ito, K., Seismic layer, reflective lower crust, surface heat flow and large inland earthquakes, Tectonophys., 306, 423-433, 1999.

Kurashimo, E., M. Tokunaga, N. Hirata, T. Iwasaki, S. Kodaira, Y. Kaneda, K. Ito, R. Nishida, and S. Kimura, Geometry of the subducting Philippine Sea plate and the crustal and upper mantle structure beneath eastern Shikoku Island revealed by seismic refraction/wide-angle reflection profiling, J. Seismol. Soc. Jpn., Ser. 2, 54, 489-505, 2002 (in Japanese and English abstract).

Langston, C. A., The effect of planar dipping structure on source and receiver responses for constant ray parameter, Bull. Seism. Soc. Am., 67, 1029-1050, 1977.

Langston, C. A., Structure under Mount Rainier, Washington, inferred from teleseismic body waves, J. Geophys. Res., 84, 4749-4762, 1979.

Li, X., S. V. Sobolev, R. Kind, X. Yuan, and Ch. Estabrook, A detailed receiver function image of the uppermantle discontinuities in the Japan subduction zone, Earth Planet. Sci. Lett., 183, 527-541, 2000.

Nakamura, M., H. Watanabe, T. Konomi, S. Kimura, and K. Miura, Characteristic activities of subcrustal earthquakes along the outer zone of southwestern Japan, Annuals of Disas. Prev. Res. Inst., Kyoto Univ., 40(B-1), 1997 (in Japanese).

Nakanishi, I., Precursors to ScS phase and dipping interface in the upper mantle beneath southwest Japan, Tectonophys., 69, 1-35, 1980.

Shibutani, T., The crust and slab structure beneath the eastern Shikoku by receiver function analyses, Monthly Chikyu, 23, 708-713, 2001 (in Japanese).

Shiomi, K., The heterogeneous structure of seismic velocity beneath the Chugoku and Shikoku districts based on receiver function analysis, Ph.D. Thesis of the Tohoku University, pp. 152, 2002 (in Japanese).

Yamane, T., I. Nakanishi, and S. Kamiya, P-wave velocity structure of the Philippine Sea plate subducting from the Nankai trough and its relation with seismicity and volcanism in Southwestern and Central Japan, Bull. Earthq. Res. Inst. Univ. Tokyo, 75, 335-374, 2000 (in Japanese).

M. Yamauchi (e-mail: yamauti@eps.nagoya-u.ac.jp), K. Hirahara, and T. Shibutani 